\title{
Efficiency of the FT-IR ATR spectrometry for the prediction of the physicochemical characteristics of Melipona subnitida honey and study of the temperature's effect on those properties
}

\author{
Ligia Bicudo de Almeida-Muradian, ${ }^{1}$ Klaus Martin $\operatorname{Stramm}^{1}$ \& Leticia M. Estevinho ${ }^{2 *}$ \\ 1 Pharmaceutical Science School, University of São Paulo, Brazil. Av. Prof. Lineu Prestes 580, bloco 14, CEP 05508-900, São Paulo, Brazil \\ 2 CIMO - Mountain Research Center, Agricultural College of Bragança, Polytechnic Institute of Bragança, Campus Santa Apolónia, \\ Bragança E 5301-855, Portugal
}

(Received 19 May 2013; Accepted in revised form 11 July 2013)

Summary The efficiency of ATR FT-IR spectrometry was compared with recommended methodologies for physicochemical parameters of eighteen samples of Melipona subnitida honey. Significant differences were found between the values obtained using those techniques for hydroxymethylfurfural, ash and electrical conductivity. The results for the other parameters did not differ significantly, suggesting that this rapid and nondestructive methodology may predict parameters usually used to assess honeys' quality. The effects of different storage conditions (room temperature, fridge and freezer) on the quality parameters of the product stored during 12 months were studied. Darkening of the honey was observed, particularly in the fridge and freezer. However, the changes occurring in the honey kept on the fridge were not statistically different from those occurring in the product kept on the freezer, except for free acidity. The results obtained for the honey stored at room temperature, best way to preserve, differed significantly from those obtained for the honey kept under the other conditions.

Keywords FT-IR ATR spectrometry, honey, Melipona subnitida, physicochemical analysis, storage conditions.

\section{Introduction}

Honey, a viscous and aromatic product widely appreciated and used in ethnomedicine since ancient times, is prepared by the bees from nectar of flowers or honeydew, being the latter produced through an intermediary, generally an aphid (Ouchemoukh et al., 2007; Ferreira et al., 2009). The appearance, flavour, sweetness and texture of this natural product, as well as its medicinal properties, have attracted consumers and, more recently, researchers (Nagai et al., 2012).

Honey contains about 200 different substances (Kucuk et al., 2007), being carbohydrates the main constituents, followed by minerals, proteins, vitamins, lipids, organic acids and amino acids (Finola et al., 2007). This product also contains components that act as preservatives such as vitamin $\mathrm{C}$, flavonoids, other phenolics and enzymes, namely glucose oxidase, catalase and peroxidase (Bertoncelj et al., 2007).

This natural product composition is rather variable, depending on the floral origin, the climate, environmental

*Correspondent: E-mail: leticia@ipb.pt and seasonal conditions, as well as processing methods (Silva et al., 2009). Indeed, the products differ not only in their chemical properties (volatile constituents, carbohydrates and phytochemicals), physical properties (colour, viscosity, hygroscopic properties and $\mathrm{pH}$ ) and taste, but also in their different biological activities (Cimpoiu et al., 2012). Modern science has made it possible to specify their medical significance for healing wounds and burns (Zohdi et al., 2012), oncology care (Bardy et al., 2008), as well as its antimicrobial factors, due to its high osmolarity, $\mathrm{pH}$, hydrogen peroxide production and the presence of other phytochemical components (Estevinho et al., 2008). The phytochemical component of honey is also responsible for its antioxidant activity, which protects cells from the damage caused by free radicals, thus decreasing the inflammation process (Molan, 2006; Alzahrani et al., 2012).

Two types of honeys are produced and commercialised in Brazil: the traditional Apis mellifera honey and that produced by the stingless bees. A. mellifera, the Africanised honeybee, is the most widespread species in Brazil (Araújo et al., 2006) and is the most intensely 
studied (Nogueira-Neto et al., 1986). The stingless bee, Melipona subnitida, is native to north-eastern Brazil. Melipona honey is not included in the international standards for honey (Codex Alimentarius, 2001) and is not controlled by the food control authorities because there is very little knowledge about this product. Furthermore, there are no quality control regulations for this honey, and therefore, there are no safety assurances for consumers.

The European Community (Council Directive, 2001) and the Brazilian Regulation (Brasil, 2000) indicate many physicochemical measurements to assess honey quality. Many analytical methods and separation techniques that allow studying the botanical and geographical origin, the physicochemical properties, bioactive compounds patterns, pollen distribution, aroma compounds and special marker compounds are referred in the literature (Cimpoiu et al., 2012).

For each measurement, a distinct analytical method has to be used, which limits the number of honey samples analysed daily in a quality control laboratory (Almeida-Muradian et al., 2012). In this context, to improve this quality control, it was necessary to develop rapid, simple and accurate methods for the routine analysis of honey.

The ATR-FTIR technique has some advantages when compared with the commonly used methodologies, which result in time- and cost-savings and enlarge the number of samples that can be analysed. It is a rapid, nondestructive method that typically does not require any sample manipulation or chemical preparations (Ruoff et al., 2006; Maia et al., 2013).

This study aims to compare the efficiency of the ATR-FTIR technique with the standard methodologies used in the determination of the physicochemical parameters of $M$. subnitida honey. In parallel, it is the objective of this work to assess the effect of different techniques and processes of conservation [room temperature $\left(25^{\circ} \mathrm{C}\right)$, fridge $\left(4{ }^{\circ} \mathrm{C}\right)$ and freezer $\left(-18{ }^{\circ} \mathrm{C}\right)$ ] on the quality parameters of Melipona honey, stored during 12 months.

This is the first study about the effect of the temperature on the quality parameters on stingless bee honey from $M$. subnitida bee.

\section{Materials and methods}

\section{Chemicals and materials}

All the chemical reagents used were purchased from Sigma Chemical Co. (St. Louis, MO, USA) and were of analytical grade. The water was purified using a Milli-Q purification system (Millipore, Bedford, MA, USA). The equipments were Shimadzu UV-Visible Spectrophotometer UV-1650 PC; Kruss-Digital Handheld Refractometer DR 201-95; HANNA HI-8322 honey colour analyser; conductivimeter Crison EC Meter Basic 30+, Tecnal TE-0363; Soxhlet extraction using Tecnal-SEBELIN TE; and the HPLC Shimadzu Prominence with Refractive Index detector model RID-10A for sugar analysis. Infrared spectra were collected by direct measurements using a Bruker Tensor 27. It was also used a Tensor 27 Sample Compartment RT-DLaTGS (Bruker Optik GmbH, Ettlingen, Germany) equipped with a MKII Golden Gate singlereflection ATR accessory (Specac Inc., Woodstock, GA, USA). The spectrometer was equipped with a DigiTechTM 163 DLATGS detector that covers a spectral range from 12000 to $370 \mathrm{~cm}-1$ and operates at room temperature. The software used was Opus 6.5 (Bruker Optik GmbH).

\section{Honey samples}

Eighteen samples of $M$. subnitida honey were harvested from the same apiary, located in Jandaira $\left(05^{\circ} 21^{\prime} 21^{\prime \prime} \mathrm{S}, 36^{\circ} 07^{\prime} 40^{\prime \prime} \mathrm{W}\right)$. After honeys' harvest, the samples were delivered to the Laboratory, where they were stored in a dark place (wrapped in aluminium, to protect from the light effect) until analysis, which occurred in no more than 1 month after the extraction from the hives by bee-keepers. Six honey samples were stored at room temperature, 6 samples were stored at fridge $\left(4{ }^{\circ} \mathrm{C}\right)$, and 6 were stored at the freezer $\left(-18{ }^{\circ} \mathrm{C}\right)$. The eighteen samples, which stored for 12 months, showed no sign of fermentation or spoilage. Those temperatures were selected because they are the most common ways to store Melipona honey, which has higher moisture and is produced in a more artisanal way than honey from $A$. mellifera. This product is, as consequence, more susceptible to fermentations and chemical alterations.

\section{Physicochemical analyses according to the standard methodologies}

Prior to the storage, physicochemical analyses were performed using the standard methodologies and the FT-IR ATR technique (the same used in AlmeidaMuradian et al., 2012) to compare their efficiency. The other physicochemical analyses using the recommended methods were performed to the products submitted to the three storage conditions after different time periods ( 4,8 and 12 months). The physicochemical parameters were analysed according to the official methods of analysis of the Association of Official Analytical Chemists (AOAC, 1990), The harmonised methods of the European Honey Commission (Bogdanov et al., 1997) and the Codex Alimentarius (2001). Samples were analysed in triplicate and during the same time period to ensure uniform conditions and comparability. 


\section{Moisture content}

Moisture was determined using the indirect refractometric method of Chataway. This method is based in the principle that refractive index increases with the solids content. All measurements were performed at $20{ }^{\circ} \mathrm{C}$, after waiting for $6 \mathrm{~min}$ for equilibrium and obtaining the corresponding percentage of moisture $(\mathrm{g}$ per $100 \mathrm{~g}$ honey) from the refractive index of the honey sample by consulting a standard table for the purpose.

\section{Free acidity}

Free acidity was determined by potentiometric titration, after homogenisation and filtration of the samples. Ten grams of honey was then dissolved in $75 \mathrm{~mL}$ of distilled water, and solution of phenolphthalein was added. The solution was titrated with $0.1 \mathrm{~N} \mathrm{NaOH}$. The milliequivalents of acid per $\mathrm{kg}$ of honey were determined as 10 times the volume of $\mathrm{NaOH}$ used in titration.

\section{Hydroxymethylfurfural}

A clarifying agent $(0.5 \mathrm{~mL}$ of Carrez I and $0.5 \mathrm{~mL}$ of Carrez II solutions) was added to five grams of honey and to $25 \mathrm{~mL}$ of distilled water. The absorbance of the filtered solution was measured at 284 and $336 \mathrm{~nm}$ against a filtered solution treated with $\mathrm{NaHSO}_{3}$. HMF was determined following the equation:

$$
\begin{aligned}
\mathrm{HMF} / 100 \mathrm{~g} \text { of honey }= & \left(\mathrm{Abs}_{284}-\mathrm{Abs}_{336}\right) \times 14.97 \times \\
& (5 / \mathrm{g} \text { of sample }) .
\end{aligned}
$$

\section{Ash content}

The ash content was determined by the gravimetric methodology. First of all, the crucible was prepared. It was heated in the electrical furnace at ashing temperature and subsequently cooled and weighted. Ten grams of the sample was transferred to the crucible, and two drops of olive oil were added. Afterwards, the sample was heated in a hot plate until carbonised. The sample was kept in the preheated furnace, at $550{ }^{\circ} \mathrm{C}$, for at least $5 \mathrm{~h}$. The following equation was used in the determination of the ash content:

$$
\begin{aligned}
& \text { Ash content } / 100 \mathrm{~g} \text { of honey } \\
& =\text { difference of crucibles weight } \\
& \text { /total weight of the sample. }
\end{aligned}
$$

\section{Electrical conductivity}

The electrical conductivity of a solution of $20 \mathrm{~g}$ dry matter of honey in $100 \mathrm{~mL}$ in deionised water was measured using an electrical conductivity cell. The determination of the electrical conductivity is based on the measurement of the electrical resistance, of which the electrical conductivity is the reciprocal.
Sugars

The determination of glucose, fructose and sucrose was performed by high-pressure liquid chromatography, using a refractive index detector. The Shim-Pack CLC-NH $2(6.0 \times 150 \mathrm{~mm})$ column, $5 \mu \mathrm{m}$, was eluted by the use of isocratic system with acetonitrile (pump A - LC 20AT Shimadzu) and water (pump B - LC 20AT Shimadzu) (80:20, v/v), previously filtered. The separation was performed at a flow rate of $1.3 \mathrm{~mL} \mathrm{~min}^{-1}$, with the column and detector temperature set at $30{ }^{\circ} \mathrm{C}$ using auto sampler (SIL20A - Shimadzu). Quantification was achieved by external calibration method, and the calibration curves ranged from 50 to $500 \mu \mathrm{g} \mathrm{mL} \mathrm{mL}^{-1}$ for glucose, fructose and sucrose. Sugar contents were expressed in g per 100 g of dry weight.

$p H$

$\mathrm{pH}$ was measured with a combined $\mathrm{pH}$ glass electrode connected to $\mathrm{pH}$ meter, in a solution prepared with $10 \mathrm{~g}$ of honey in $75 \mathrm{~mL}$ of distilled water.

\section{Colour}

Honey's colour was determined using a photometer with direct read-out in $\mathrm{mm}$ Pfund, a set of 5 measurement cuvettes and analytical grade glycerine for accurate calibration. Honey colour is measured in millimetres on the Pfund scale compared with an analytical standard scale of reference on the graduation of glycerine.

\section{Attenuated total reflection (FT-IR ATR) technique}

The determinations using the FT-IR ATR technique were performed, prior to the storage, as recommended by Almeida-Muradian et al. (2012). The samples were heated at $55^{\circ} \mathrm{C}$ for $8 \mathrm{~h}$ and then cooled to room temperature before further analysis. After pretreatment, a drop of the sample was applied to the surface of the diamond. The measuring cell consists of a diamond with a refractive index of 2.4 at $1000 \mathrm{~cm}^{-1}$. The depth of penetration of the infrared radiation is $2.0 \mu \mathrm{m}$ at $1000 \mathrm{~cm}^{-1}$ for a sample with a refractive index of 1.5, which corresponds to the refractive index of honey. It was left to thermally equilibrate for $4 \mathrm{~min}$. One hundred scans were recorded for each spectrum in the wave number ranged between 400 and $550 \mathrm{~cm}^{-1}$ with a spectral resolution of $4 \mathrm{~cm}^{-1}$. Single beam spectra of all samples were recorded and rationed against the background spectrum of the clean diamond surface to present the spectra in absorbance. The crystal surface was cleaned between the samples with Triton X-100 solution $(1 \% \mathrm{w} / \mathrm{w})$ and rinsed with distilled water. The spectral baseline recorded by the spectrometer was examined visually to ensure that the crystal did not have residues from previous samples, as recommended by Hennessy et al. (2010). For the development of the chemometric PLS regression 
model, the IR spectra of honey samples with known composition were used to calculate a calibration function (mathematical model), which can be used for the analysis of future unknown samples, after evaluation of its capacity of prediction by internal and external validation. This part was completely based on the model described by Ruoff et al. (2006).

\section{Statistical analysis}

All the experiments were performed in triplicate $(n=3)$, and the results were expressed as mean \pm standard deviation. The studies were conducted in a fully randomised manner, and all the obtained data were tested regarding normal distribution (Shapiro-Wilk test) and homogeneity of variances (Levene and Brown-Forsythe tests). After ensuring that it could be used parametric statistical tests of mean comparison, the comparisons were made by one-way ANOva followed by Tukey's test. In the data sets that did not follow normal distributions and homogeneity of variances, it was used the nonparametric Mann-Whitney test. The $P$ values $\leq 0.05$ were evaluated as statistically significant. This treatment was carried out using SPSS, version 18 (IBM Software, Armonk, NY, USA).

\section{Results and discussion}

The results obtained for the physicochemical parameters analysed before the storage using the standard methodologies and the FT-IR ATR technique are presented in Table S1.

Increasing demands for fast and inexpensive methods for the assessment of food quality have stimulated the development of methods applicable for this purpose where high-speed and easy-to-use analytical techniques capable of providing a straightforward assessment of honey authenticity are needed (Cozzolino et al., 2011). FT-IR ATR spectroscopy has the advantages of being rapid and nondestructive, requires a very small amount of sample and predicts many parameters at the same time. Figure S1 depicts a typical spectrum of honey samples using this type of spectroscopy and the peaks attributed to the components that were determined $(\mathrm{v}=$ stretching; $\delta=$ deformation, at the vibrational mode).

The moisture content influences honey colour, viscosity, flavour, density and refractive index, and it is one of the most important physicochemical parameters for the analysis of conservation and stability of foods in general (Cano et al., 2001). Indeed, it is the only composition criterion, which as a part of the honey standard has to be fulfilled in world honey trade (Iglesias et al., 2012). The M. subnitida honey possesses higher moisture content than A. mellifera honey, which could, in theory, accelerate crystallisation and increase its water activity to values where certain yeasts could grow. However, due to the presence of polyphenols and to the cerumen enzymatic processing by bees in the hive, Melipona honeys are fairly resistant to spoilage by unwanted fermentation (Vit et al., 2004; Souza et al., 2006). Before storage, the moisture content obtained for the stingless bees' honey was $24.93 \pm 0.95 \mathrm{~g}$ per $100 \mathrm{~g}$, using the standard methodologies and $25.08 \pm 1.80 \mathrm{~g}$ per $100 \mathrm{~g}$ using the FT-IR ATR technique. Significant differences $(P=0.91)$ were not found between the two methodologies. The prediction of this parameter obtained by Almeida-Muradian et al. (2012) for A. mellifera Swiss honey was also good.

The free acidity of stingless bees' honey is generally higher, which justifies the more acidic flavour of this type of honey, responsible for the higher consumers' preference (Vit et al., 2004; Almeida-Muradian, 2013). Free acidity is due to the presence of organic acids, particularly gluconic acid, which are in equilibrium with the corresponding lactones and some inorganic ions such as phosphate or sulphate (Gomes et al., 2009). In the present study, significant differences $(P=0.19)$ were not found between the results obtained with the two methodologies for fresh honey: $24.87 \pm 2.10$ (standard methodologies) and $21.46 \pm 3.03$ (FT-IR ATR technique). Guerrini et al. (2008), who studied three samples of stingless bee honey from the Ecuador, found similar values for the fresh honey.

Elevated concentrations of HMF in honey provide an indication of overheating, storage in poor conditions or age of the honey, because HMF and congener compounds are spontaneously formed in carbohydratecontaining foods by the Maillard reaction (the nonenzymatic browning) or the acid-catalysed dehydration of hexoses (Spano et al., 2006). The results obtained for the HMF were significantly different between the two methodologies under study $(P=0.009)$. The values obtained using the standard methodologies and using the FT-IR ATR technique were $8.60 \pm 0.98$ and $16.41 \pm 1.79 \mathrm{mg} \mathrm{kg}^{-1}$, respectively. Our results are corroborated by the observations of Almeida-Muradian et al. (2012), who found that the FT-IR ATR technique is not adequate to predict honeys' HMF, in the product by neither $A$. mellifera nor $M$. subnitida.

The ash content is a complex function of the floral, geographical, soil and climatic characteristics and conditions (Iglesias et al., 2012). The determination of this parameter gives an insight into the honeys' quality and allows distinguishing between blossom and honeydew honeys (Andrade et al., 1999). This was the parameter in which higher significant differences were found $(P=0.004)$ between the values obtained using the recommended methodology $(0.04 \pm 0.01 \mathrm{~g}$ per $100 \mathrm{~g}$ ) and applying the FT-IR ATR spectroscopy $(0.87 \pm 0.24 \mathrm{~g}$ per $100 \mathrm{~g})$. 
The electrical conductivity is very often used in routine honey control and is related to the ash and acid content of honey that reflects the presence of ions and organic acid (Adenekan et al., 2010). The electrical conductivity assessed by the standard methodologies $\left(132.45 \pm 33.28 \mu \mathrm{S} \mathrm{cm}^{-1}\right)$ and by using the FT-IR ATR technique $\left(372.15 \pm 45.42 \mu \mathrm{S} \mathrm{cm}^{-1}\right)$ was significantly different by the Tukey's test $(P=0.037)$.

Honey is an extremely varying supersaturated sugar solution, being fructose the dominant, followed by glucose and sucrose (Iglesias et al., 2012). In this study, the values obtained for fructose were $31.14 \pm 1.84$ and $29.90 \pm 1.10 \%$, using the standard and nonstandard methodologies, respectively. The values obtained using the recommended methodologies and FT-IR ATR spectroscopy were equal to $23.23 \pm 1.57$ and $27.10 \pm$ $4.81 \%$, for glucose and $5.73 \pm 0.97$ and $6.38 \pm 0.93 \%$ for fructose. Significant differences were not found between the two methodologies under study in the determination of the carbohydrates' composition of stingless bees' honey.

The tendency of honeys to granulate is directly related to some sensitive parameters such as the ratios fructose/glucose and glucose/moisture. These crystallisation indexes are also important in the identification of the botanical origin of the product (Ruoff et al., 2006). The value obtained for the ratio fructose/glucose with the standard methodology was $1.34 \pm 0.06$ and was equal to $1.12 \pm 0.12$ using the FT-IR ATR spectroscopy. Regarding the ratio glucose/moisture, the values obtained were $0.93 \pm 0.02$ (recommended methods) and $1.09 \pm 0.15$ (FT-IR ATR). Because the fructose/glucose ratio is lower than 1.40 and the glucose/water ratio is lower than 1.70 , it is expected that the samples under study will crystallise slowly, even though this behaviour can be strongly affected by the heat and storage conditions.

The $\mathrm{pH}$ of a honey is not directly related to the free acidity because of the buffering action of the various acids and present minerals. This parameter is of great importance during the extraction and storage of honey because it influences its texture, stability and shelf lifetime (Gomes et al., 2009). The value obtained for the $\mathrm{pH}$ of the samples using the common methodologies $(3.90 \pm 0.19)$ was not significantly different $(P=0.84)$ from the obtained using FT-IR technique $(3.87 \pm 0.22)$. These values were very similar to the reported by Silva et al. (2009), who analysed nine samples of $M$. subnitida honey from two semi-arid regions within the state of Paraiba, Brazil.

Honey colour is related to the pollen, mineral content and phenolic compounds present and varies according to the geographical origin and botanical varieties visited by the bees (Ramalhosa et al., 2011). The results obtained for colour using the two methodologies were not significantly different: $7.00 \pm 0.19$ mm Pfund (standard methodologies) and $7.23 \pm 0.24$ (FT-IR ATR technique).

In Table S2, the results obtained for the physicochemical parameters of the M. subnitida honey after 4, 8 and 12 months of storage at the room temperature, on the fridge and on the freezer, are presented. To assess these parameters, the standard methodologies were used, not the FT-IR ATR technique, because further tests involving a greater number of samples are needed to validate this method prior to its common use at the laboratory.

The honey kept at the room temperature presented lower moisture content than the product stored on the fridge and higher content than the honey kept on the freezer after 4 and 8 months of storage. However, significant differences were not found between the three storage conditions after these periods. After 12 months, the moisture content of the honey kept at room temperature differed significantly $(P<0.05)$ from the water content of the products submitted to the other storage conditions. The higher moisture content of the honey kept on the fridge and on the freezer during one year may be due to the crystallisation, because it involves the coexistence of both crystalline and liquid phases during certain time. In the remaining liquid phase, the water activity becomes greater than that of the original liquid honey because, as consequence of crystal formation, the solid phase releases water (Tosi et al., 2004).

Concerning the free acidity, it remained almost constant from the beginning to 12 th month, with a slight tendency to increase, in all the storage conditions. It was significantly higher in the product kept at room temperature, after 4 and 8 months of storage. The free acidity of the honey stored at the fridge was also significantly higher than that of the product kept at the freezer, after 4 and 8 months. After 12 months of storage, significant differences were not found between the free acidity of the product kept at room temperature $\left(31.04 \pm 0.49 \mathrm{mEq} \mathrm{kg}{ }^{-1}\right)$ and of the honey kept on the fridge $\left(30.18 \pm 0.39 \mathrm{mEq} \mathrm{kg}{ }^{-1}\right)$, but these values differed significantly from those obtained for the frozen honey $\left(24.77 \pm 0.16 \mathrm{mEq} \mathrm{kg}^{-1}\right)$. As far as we know, the effect of the storage temperature on this parameter has never been assessed in stingless bees' honey, and the studies available for A. mellifera honey are scarce and only focus on storage at room temperature. Bath \& Singh (1999) also observed discrete increases in the free acidity of Helianthus annuus and Eucalyptus lanceolatus honey samples, after 1 year. It is known that free acidity changes are likely to occur because enzymes, such as glucose oxidase, which are active after honey harvesting, may increase the value of this parameter (Cavia et al., 2007). In this context, the lower free acidity of the frozen product may be related to a decreased activity of that enzyme, induced 
by the lower temperature, because the optimum temperature of glucose oxidase is reported to be 25 $30{ }^{\circ} \mathrm{C}$ (Banker et al., 2009).

During the 12 months of storage, statistical differences were not found between the HMF of the stingless bees' honey stored on the fridge and on the freezer. The HMF values obtained for these last two conditions were lower than those obtained for the honey stored at room temperature. This difference was already expected because the HMF is the most important intermediate product of 2 reactions: the acid-catalysed degradation of hexose and the decomposition of 3-deoxyosone in Maillard reaction, and it is the most used index to measure honey overheating and/or ageing (Wang et al., 2004; Fallico et al., 2006) who studied buckwheat honey produced by $A$. mellifera bees obtained similar results: the HMF of the product kept on the freezer and the fridge did not suffer changes during the storage, but the HMF of the honey stored at the room temperature increased gradually with the time of storage. However, the HMF values did not exceed the limits $\left(40 \mathrm{mg} \mathrm{kg}^{-1}\right)$ established by the Codex Alimentarius and European Union, because high values of HMF may be related to mutagenic activity.

During the period under study, the electrical conductivity of the honeys kept on the fridge and the freezer was not significantly different $(P>0.05)$. On the other hand, the electrical conductivity of the product kept at room temperature was always significantly different. It was verified that after 4 and 8 months of storage, the electrical conductivity was lower on the product stored at room temperature $(203.33 \pm 1.82$ and $229.50 \pm 1.09$, respectively). However, after 12 months of storage, the honey with higher electrical conductivity was the one stored at room temperature $\left(285.67 \pm 6.22 \mu \mathrm{S} \mathrm{cm}^{-1}\right)$. As far as we know, the effect of the storage on the electrical conductivity of stingless bees' honey has never been assessed before hampering the results' comparison.

The sugars studied during the storage period were fructose and glucose, because, as they are the dominant carbohydrates, it was expected that the major changes would involve them. In addition, the losses of monosaccharide are important to sensorial properties because they can correspond to chemical degradations with furyl derivatives and acids as end products or compounds associated with the Maillard reaction, which have strong organoleptic properties (CastroVázquez et al., 2008). In the present study, marked differences in the concentration of sugars during the 12 months and between the different storage conditions were not found, suggesting that the sensorial properties of the product were preserved.

The parameter that varied the most during the storage was the colour, which is the first sensory property perceived by the consumers, who generally prefer light honey. As such, variations in honey colour must receive special attention. The darkening of the honey submitted to all the conditions was observed, particularly in the product kept on the fridge and freezer. Indeed, during extended storage, lipids may generate carbonilic compounds through oxidation and promote browning (Taoukis \& Labuza, 1996). In addition, according to Bulut \& Kilic (2009), the polyphenols can form brown complexes with amino acids and proteins, and the quinones produced by oxidation of polyphenols can be involved in complex reactions leading to honeys' darkening. The greater values obtained for the frozen and cooled honey can be attributed to the crystallisation of the product, because the crystals may have influenced the optical reading of the honey colour analyser.

\section{Conclusions}

Significant differences were found between the recommended methodologies and the FT-IR ATR spectrometry for three parameters (HMF, ash and electrical conductivity) of nine analysed. Thus, the FT-IR ATR technique, which allows predicting many parameters at the same time, provides satisfactory screening results for many measurements used in routine quality control of honey even though the calibration of the equipment was performed using $A$. mellifera honey samples.

The changes in the physicochemical parameters of the M. subnitida honey stored on the fridge were not statistically different from those occurring in the product kept on the freezer, except for free acidity. Regarding the honey stored at room temperature, significant differences were obtained for most of the parameters, when compared with the other conditions.

The best storage condition for this type of honey, particularly concerning colour, is the room temperature, even though the HMF value increases significantly more in this condition. However, microbiological and sensory analyses need to be carried out in order to complete this preliminary study.

\section{Acknowledgments}

The first author thanks Peter Gallman, Rene Badertscher and Christina Kast from the Swiss Bee Research Centre, for the use of the FT-IR equipment. The authors declare that there are no conflict of interests.

\section{References}

Adenekan, M.O., Amusa, N.A., Lawal, A.O. \& Okpeze, V.E. (2010). Physico-chemical and microbiological properties of honey samples obtained from Ibadan. Journal of Microbiology and Antimicrobials, 2, 100-104. 
Almeida-Muradian, L.B. (2013). Tetragonisca angustula pot-honey compared to Apis mellifera honey from Brazil. In: Pot Honey (edited by P. Vit, R.M. Silvia, S.R.M. Pedro, W. David \& D.W. Roubik), Pp. 375-382. London: Pot-Honey Springer.

Almeida-Muradian, L.B., Luginbühl, W., Badertscher, R. \& Gallmann, P. (2012). Generalizability of PLS calibrations with FT-IR ATR spectrometry for the prediction of some physicochemical measurands of honey - Technical-scientific information. Schweizerische Eidgenossenschaft, 1, 16.

Alzahrani, H.A., Boukraâ, L., Bellik, Y. et al. (2012). Evaluation of the antioxidant activity of three varieties of honey from different botanical and geographical origins. Global Journal of Health Science, 4, 191-196.

Andrade, P.B., Amaral, M.T., Isabel, P., Carvalho, J.C.M.F., Seabra, R.M. \& Cunha, A.P. (1999). Physicochemical attributes and pollen spectrum of Portuguese heather honeys. Food Chemistry, 66, 503-510.

AOAC. (1990). Official methods of Analysis of AOAC International 15th edn. Virginia, USA: Arlington.

Araújo, D.R., Silva, R.H.D \& Sousa, S.J.. (2006). Avaliação da qualidade físico-química do mel comercializado na cidade de Crato, CE. Revista de Biologia e Ciências da Terra, 6, 5155 .

Banker, S.B., Bule, M.V., Singhal, R.S. \& Ananthanarayan, L. (2009). Optimization of Aspergillus niger fermentation for the production of glucose oxidase. Food and Bioprocess Technology, 2, 344-352.

Bardy, J., Slevin, N.J., Mais, K.L. \& Molassiotis, A. (2008). A systematic review of honey uses and its potential value within oncology care. Journal of Clinical Nursing, 17, 2604-2623.

Bath, P.K. \& Singh, N. (1999).A comparison between Helianthus annuus and Eucalyptus lanceolatus honey. Food Chemistry, 67, 389-397.

Bertoncelj, J., Doberšek, U., Jamnik, M. \& Golob, T. (2007). Evaluation of the phenolic content, antioxidant activity and colour of Slovenian honey. Food Chemistry, 105, 822-828.

Bogdanov, S., Martin, P., Lullmann, C., Borneck, R., Flamini, C. \& Morlot, M. (1997). Harmonised methods of the European honey Commission. Apidologie, 28, 1-59.

Brasil. Instrução Normativa n.11, de 20 de outubro de. (2000). Available at: http://agricultura.gov.br.

Bulut, L. \& Kilic, M. (2009). Kinetics of hydroxymethylfurfural accumulation and color change in honey during storage in relation to moisture content. Journal of Food Processing and Preservation, 33, 22-32.

Cano, C.B., Felsner, M.L. \& Bruns, R.E. (2001). Comparison of methods for determining moisture content of Citrus and Eucalyptus Brazilian honeys by refractometry. Journal of Food Composition and Analysis, 14, 101-109.

Castro-Vázquez, L., Díaz-Maroto, M.C., González-Viñas, M.A., de la Fuente, E. \& Pérez-Coello, M.S. (2008). Influence of storage conditions on chemical composition and sensory properties of citrus honey. Journal of Agricultural and Food Chemistry, 6, 19992006.

Cavia, M.M., Fernandez-Muinõ, M.A., Alonso-Torre, S.R., Huidobro, J.F. \& Sancho, M.T. (2007). Evolution of acidity of honeys from continental climates: influence of induced granulation. Food Chemistry, 100, 1728-1733.

Cimpoiu, C., Hosu, A., Miclaus, V. \& Puscas, A. (2012). Determination of the floral origin of some Romanian honeys on the basis of physical and biochemical properties. Spectrochimica Acta Part A, 100, 149-154.

Codex Alimentarius. (2001). Revised Codex Standard for Honey, Codex STAN 12-19811.

Council Directive 2001/110/CE concerning honey, Official Journal of European Communities Jan 12th 2002, L10/4752.

Cozzolino, D., Cynkar, W.U., Shah, N. \& Smith, P. (2011). Multivariate data analysis applied to spectroscopy: potential application to juice and fruit quality. European Food Research and Technology, 44, 1888-1896.

Estevinho, M.L., Pereira, A.P., Moreira, L., Dias, L.G. \& Pereira, E. (2008). Antioxidant and antimicrobial effects of phenolic compounds extracts of Northeast Portugal honey. Food and Chemical Toxicology, 46, 3774-3779.

Fallico, B., Arena, E., Verzera, A. \& Zappalá, M. (2006). The European food legislation and its impact on honey sector. Quality Assurance for Chemistry, 11, 49-54.

Ferreira, I.C.F.R., Aires, E., Barreira, J.C.M. \& Estevinho, L.M. (2009). Antioxidant activity of Portuguese honey samples: different contributions of the entire honey and phenolic extract. Food Chemistry, 114, 1438-1443.

Finola, M.S., Lasagno, M.C. \& Marioli, J.M. (2007). Microbiological and chemical characterization of honeys from central Argentina. Food Chemistry, 100, 1649-1653.

Gomes, S., Dias, L., Moreira, L., Rodrigues, P. \& Estevinho, M.L. (2009). Physicochemical, microbiological and antimicrobial properties of commercial honeys from Portugal. Food and Chemical Toxicology, 48, 544-548.

Guerrini, A., Bruni, R., Maietti, S. et al. (2008). Ecuadorian stingless bee (Meliponinae) honey: a chemical and functional profile of an ancient health product. Food Chemistry, 114, 1413-1420.

Hennessy, S., Downey, G. \& O'Donnell, C.P. (2010). Attempted confirmation of the provenance of Corsican PDO honey using FT-IR spectroscopy and multivariate data analysis. Journal of Agricultural and Food Chemistry, 58, 9401-9406.

Iglesias, I., Feás, X., Rodrigues, S. et al. (2012). Comprehensive study of honey with protected denomination of origin and contribution to the enhancement of legal specifications. Molecules, 17, $8561-8577$.

Kucuk, M., Kolayli, S., Karaglu, S., Ulusoy, E., Baltaci, C. \& Candan, F. (2007). Biological activities and chemical composition of three honeys of different types from Anatolia. Food Chemistry, 100, 526-534.

Maia, M., Barros, A.I.R.N.A., Fernando, M. \& Nunes, F.M. (2013). A novel, direct, reagent-free method for the detection of beeswax adulteration by single-reflection attenuated total reflectance midinfrared spectroscopy. Talanta, 107, 74-80.

Molan, P. (2006). Using honey in wound care. International Journal of Aromatherapy, 3, 21-24.

Nagai, T., Inoue, R., Inoue, H. \& Suzuki, N. (2012). Preparation and antioxidant properties of water extract of propolis. Food Chemistry, 80, 29-33.

Nogueira-Neto, P., Imperatriz -Fonseca, V. L. \& Kleinert -Giovannini, A. (1986). Biologia e manejo das abelhas sem ferrão. São Paulo: Tecnapis, 54p.

Ouchemoukh, S., Louaileche, H. \& Schweizer, P. (2007). Physicochemical characteristics and pollen spectrum of some Algerian honey. Food Control, 18, 52-58.

Ramalhosa, E.E., Gomes, T.T., Pereira, A.P., Dias, T.T. \& Estevinho, L.M. (2011). Mead production tradition versus modernity. Advanced Food Nutritional Research, 63, 101-118.

Ruoff, K., Iglesias, M.T.R., Luginbuhl, W., Bosset, J., Bogdnov, S. \& Amado, R. (2006). Quantitative analysis of physical and chemical measurands in honey by mid-infrared spectrometry. European Food Research and Technology, 223, 22-29.

Silva, L.R., Videira, R., Monteiro, A., Valentão, P. \& Andrade, P. (2009). Honey from Luso region (Portugal): physicochemical characteristics and mineral contents. Microchemical Journal, 93, 73-77.

Souza, B., Roubik, D., Barth, O.M. et al. (2006). Composition of stingless bee honey: setting quality standards. Interciencia, 31, $867-875$

Spano, N., Casula, L., Panzanelli, A., Pilo, M.I., Piu, P.C. \& Scanu, R. (2006). An RP-HPLC determination of 5-hydroxymethylfurfural in honey. The case of strawberry tree honey. Talanta, 68, $1390-1395$. 
Taoukis, P. \& Labuza, T.P. (1996). Summary: integrative concepts. In: Food Chemistry, 3rd edn. (edited by O.R. Fennema) Pp. 1013-1041. New York: Marcel Dekker Inc.

Tosi, E.R.E., Lucero, H. \& Bulacio, L. (2004). Effect of honey hightemperature short-time heating on parameters related to quality, crystallization phenomena and fungal inhibition. LWT - Food Science and Technology, 37, 669-678.

Vit, P., Medina, M. \& Enriquez, M.E. (2004). Quality standards for medicinal uses of Meliponinae honey in Guatemala, Mexico and Venezuela. Bee World, 85, 2-5.

Wang, X.H., Gheldof, N. \& Engeseth, N.J. (2004). Effect of processing and storage on antioxidant capacity of honey. International Journal of Food Science and Technology, 69, 96-101.

Zohdi, R.M., Zakaria, Z.A.B., Yusof, N., Mustapha, N.M. \& Abdullah, M.N.H. (2012). Gelam (Melaleuca spp.) honey-based hydrogel as burn wound dressing. Evidence-Based Complementary and Alternative Medicine, 2010, Article ID 843020035, 1-7.

\section{Supporting Information}

Additional Supporting Information may be found in the online version of this article:

Figure S1. Typical spectrum (FT-IR ATR) of honey samples $(\mathrm{v}=$ stretching; $\delta=$ deformation, at the vibrational mode).

Table S1. Results obtained for the physicochemical analysis performed to the eighteen samples of Melipona subnitida honey using the standard methodologies and the FT-IR ATR technique.

Table S2. Physicochemical parameters of the Melipona subnitida honey after 4,8 and 12 months of storage at the room temperature, on the fridge and on the freezer. 